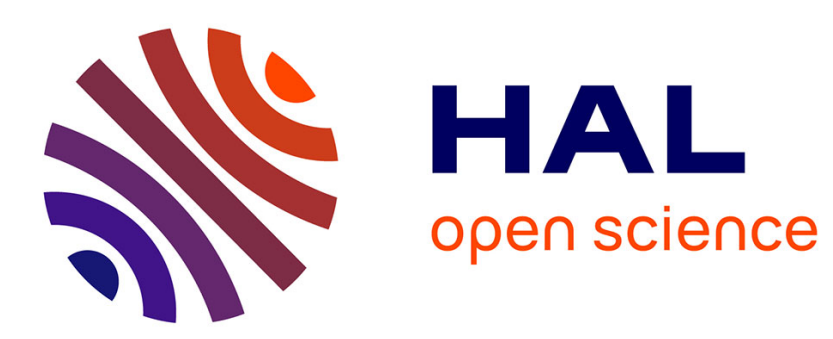

\title{
Social transmission of food handling in the context of triadic interactions between adults and young canaries (Serinus canaria)
}

\author{
Nicole Cadieu, P. Winterton, J.C. Cadieu
}

\section{To cite this version:}

Nicole Cadieu, P. Winterton, J.C. Cadieu. Social transmission of food handling in the context of triadic interactions between adults and young canaries (Serinus canaria). Behavioral Ecology and Sociobiology / Behavioural Ecology and Sociobiology, 2008, 62 (5), pp.795-804. hal-00320098

\section{HAL Id: hal-00320098 \\ https://hal.science/hal-00320098}

Submitted on 10 Sep 2008

HAL is a multi-disciplinary open access archive for the deposit and dissemination of scientific research documents, whether they are published or not. The documents may come from teaching and research institutions in France or abroad, or from public or private research centers.
L'archive ouverte pluridisciplinaire HAL, est destinée au dépôt et à la diffusion de documents scientifiques de niveau recherche, publiés ou non, émanant des établissements d'enseignement et de recherche français ou étrangers, des laboratoires publics ou privés. 


\section{Social transmission of food handling in the context of}

2 triadic interactions between adults and young canaries

3 (Serinus canaria)

4

5 N. Cadieu $^{1}$, P. Winterton ${ }^{2}$ and J.C. Cadieu ${ }^{1}$

6

$7 \quad{ }^{1}$ Centre de Recherches sur la Cognition Animale, CNRS-Université Paul-Sabatier, Toulouse, 8 France

$9 \quad{ }^{2}$ Université Paul Sabatier, 118 route de Narbonne, 31062 Toulouse cedex 4, France.

11 Running headline: Cadieu, Winterton, Cadieu: Transmission of food handling in the canary

13 Keywords: Social transmission, Food handling, Familiarity, Social recognition, Serinus 14 canaria.

Correspondence: Cadieu, Centre de Recherches sur la Cognition Animale, CNRS-Université Paul Sabatier Toulouse III-UMR 5169, 118 Route de Narbonne, 31062 Toulouse Cedex 4, France, email: cadieu@cict.fr 


\section{ABSTRACT}

2 We studied the factors that enhance food recognition and consumption in young canaries when

3 confronted with adults. In contrast to previous studies on canaries in which social transmission

4 of food habits was studied in the context of dyadic interactions (one juvenile - one adult), we

5 proposed a more realistic framework in which young canaries were studied in the context of

6 triadic interactions, free or not, with adults of both sexes. We found that during free

7 interactions, the young bird only eats with a familiar male, and that this association enhances

8 the social transmission of seed handling. When the juvenile was separated from the adults by a

9 transparent partition, it only learned to husk seed if it was present at the feeder at the same

10 time as a familiar adult acting as a demonstrator. The presence of adults that are familiar but

11 do not act as demonstrators does not facilitate social transmission of handling. However, the

12 presence of a familiar, demonstrating female had also no effect on this transmission.

13 Coordination of the actions of the experienced bird and of the naïve subject is required for

14 social transmission to occur. Action coordination does not depend solely on the level of

15 familiarity between partners, but also on the role played by the demonstrator (here, the adult

16 male) that looks after the juvenile during its transition towards independence. 
1 For young mammals and birds, becoming independent is a risky transition as adults tend to

2 abandon the young (Trivers 1974; Davies 1976) and many inexperienced juveniles may die of

3 starvation due to a lack of alimentary knowledge (Diamond 1987; Sutherland 1998). Indeed,

4 young animals must not only learn to recognize appropriate food sources but also how to

5 handle them. One solution to this problem is provided by the social transmission of the

6 information required for successful recognition and handling of food. Field observations have

7 shown that some birds and mammals learn new feeding habits under the influence of their

8 parents or within family groups (Norton-Griffiths 1966; Goodall 1973; Terkel 1996; Midford

9 et al. 2000; Biro et al. 2003). In contrast, the transmission of feeding information from adults

10 to their progeny has seldom been studied in laboratory conditions. The usual method

11 employed to study the influence of familiarity, familial bonds and kinship on social

12 transmission consists of separating naïve and experienced individuals by means of a

13 transparent partition enabling to watch the activity of the experienced subject and then testing

14 the performance of the naive subject. By means of this experimental approach, it has been

15 shown that familiarity rather than relatedness favours social transmission between individuals

16 of two generations (Chesler 1969; Hatch and Lefebvre 1997). For instance, cats (Felis catus)

17 learn an instrumental task from their mothers more easily than from an unknown female but

18 the difference disappears after familiarization with the unrelated cat (Chesler 1969). The

19 positive influence of familiarity on social learning indicates that the amount of attention that

20 demonstrators attract from observers varies with familiarity (Benskin et al. 2002).

Social or individual recognition seems to orient the direction in which information on

22 food sources is transmitted. Coussi-Korbel and Fragaszy (1995) consider tolerance to be a

23 crucial factor in the spread of knowledge about food resources through the population of

24 primates ; by 'tolerance' they mean the absence of aggression between the partners of an 
1 interaction. Therefore, reducing interactions to a pure observational component (e.g. watching

2 a parent through a transparent partition) does not take into account that in natural conditions,

3 animals freely interact (Midford et al. 2000). Coussi-Korbel and Fragaszy (1995), hypothesize

4 that simultaneous access to food source and coordination between the activities of experienced

5 and inexperienced partners are required for social learning of new food habits. Various

6 authors (Terkel 1996; Midford et al. 2000; Caldwell and Witten 2003) observed that in birds,

7 rodents and monkeys, access to food reward is necessary for complete successful social

8 learning of foraging behaviour. In addition, in certain mammals and birds, adults exhibit a

9 tendency to actively incite the young to access the food (Meinertzhagen 1954; Nicol and Pope

10 1996; Sherry 1977; Caro and Hauser 1992; Wauters et al. 1999). However, simultaneous

11 access to the food resource can also have negative effects on social learning (Beauchamp and

12 Kacelnik 1991, Giraldeau and Lefevre 1987).

It is therefore particularly interesting to study the role played by adults in the

14 acquisition of feeding habits by young animals and the way in which adults influence such

15 habits. From this perspective, experiments in which young, naïve subjects are confronted with

16 a unique adult demonstrator are limited in terms of the conclusions that can be extracted with

17 respect to a social framework. Indeed, in natural context, juveniles experience multiple rather

18 than dyadic interactions as they may perceive and learn sometimes from both parents (triadic

19 interaction) and not just from one of them (dyadic interaction).

In birds that are territorial breeders both adults may participate in rearing the young. In

21 this case, it is important to determine whether or not only familiar adults enhance the 22 acquisition of feeding habits. Furthermore, it is also relevant to study whether each of the 23 adults has the same influence on such acquisition. In canaries (erinus canaria), both males 24 and females participate together in parental care in natural conditions and are therefore equally 
1 familiar to the juvenile. However, after fledging, the parents contribute unequally to juvenile

2 rearing. The question therefore arises as to whether it is the particular role played by the adult

3 at a given moment in the life of the young bird (in the present case, after fledging) which

4 determines the choice of the model. In the young canary interaction with experienced adults

5 accelerates the use of specific seeds as food (Cadieu and Cadieu, 1996 1998; Cadieu et al.

6 1995a,b). Juveniles tend to choose the same type of seeds selected by a demonstrator.

7 Moreover, husking of a given type of seed is only facilitated if juveniles observe the same type

8 of seed being husked (Cadieu et al. 1995a). Studies of dyadic interactions showed that

9 familiarity with the adult also plays a role in the acquisition of feeding habits (Cadieu and

10 Cadieu 2004). Allowing the young to access the seed at the same time as the adult male in the

11 context of free interactions improved the acquisition and transmission of the husking

12 technique only if the male was familiar. However, this study (Cadieu and Cadieu 2004) did

13 not identify the processes through which the involvement of the young in the activities of the

14 familiar male enhanced the acquisition of efficient husking.

In the present investigation, we studied the factors that enhance food recognition when the young bird has access to seed together with the adults and that facilitate the acquisition of 17 the skills required for the use of the seed. In contrast to our previous work (Cadieu and Cadieu 18 2004), in which dyadic interactions between a juvenile and a given parent were studied, here 19 we proposed a more realistic framework in which young canaries were studied in the context 20 of triadic interactions with adults of both sexes. Thus, the goal of the present work was not 21 only to verify whether or not our previous findings apply in the case of triadic interactions but 22 to determine whether this experimental context uncovers new forms of food habit acquisition 23 that may have been unnoticed so far. We analyzed whether in the context of free triadic 24 interactions, a juvenile prefers to associate with one or both familiar adults that raised him or 
1 with one or two individuals that did not raise him but that had a privileged relationship with

2 him during the period of emancipation. In our experiments, pairs of demonstrators that could

3 be familiar or unfamiliar were used and young birds could freely interact with both of them. In

4 order to assess the effect of such free interactions, we studied in parallel non-free triadic

5 interactions in which juveniles could see both adults through a partition but not interact with

6 them. Our goal was to determine whether both adults are equally used as a model by the

7 juvenile. Furthermore, we wanted to know whether juveniles acquire an efficient food

8 handling alone, based on having access to seed in the presence of adults, or based on

9 consuming seed kernels husked by the model(s) and/or through co action with the model(s).

METHODS

\section{Subjects and Housing}

14 The canaries used were bred in our laboratory. Young birds were reared by their own parents 15 in cages measuring $60 \times 30 \mathrm{~cm}$ and $35 \mathrm{~cm}$ high. They were maintained at $25 \pm 1^{\circ} \mathrm{C}$ under a 16 15:9 h light: dark cycle. Brood size was two to four individuals. When females laid more than 17 four eggs, the last eggs were removed within two days of the end of laying. The parents had 18 access to various types of seed (except hemp seed), greens and mash during the brooding and 19 rearing period. When the young birds fledged at around 18 days after hatching, we removed 20 the seeds, and both adults and juveniles had access to greens and mash exclusively. Thus, the

21 juveniles were naïve with respect to seeds because they did not have the opportunity to learn

22 how to husk and eat them. For the experiment, we used one young bird from each brood.

23 Juveniles were chosen at random when they were $28 \pm 1$ day old. At that age, canaries are able 
1 to pick up and ingest soft food such as mash, but are still fed by their parents. Each bird was

2 tested only once in a single experimental condition. The sex of the offspring was determined

3 after the study through behavioral observations made following sexual maturity.

4

5

6 To make the conditions as homogeneous as possible for comparisons between juveniles in the

7 presence of their parents or in the presence of an unfamiliar couple, the families of canaries

8 with young of the same age were transferred to the experimental box just after the young had

9 fledged. Families of birds were separated by opaque panels. In the families of canaries

10 selected for the tests, the females started to lay a new clutch before the juveniles had reached a

11 suitable age for testing. At the moment of the tests, all females were at the same stage of

12 incubation. Plastic eggs were then used to replace the real ones. To avoid the death of

13 embryos, the eggs removed were transferred to the nests of other females, incubating

14 unfertilized eggs. The adult demonstrators were familiar with hemp seed because they had

15 been fed with it before they reared the young.

Prior to the test, the juveniles were removed and placed for 20 minutes in a cage distant from the adults in order to reduce the disturbance brought about by the actual test procedure. During this period, the cage housing the adult pair of birds was fitted out for the test. The parents' cage or the cage of an unfamiliar pair of birds was used for the test. The other cages were kept distant from the experimental box. The cage was fitted at either end with a feeder containing mash and a drinking trough full of fresh water.

During the study of free interactions, the birds were able to move within the cage, which was equipped with four parallel perches, $12 \mathrm{~cm}$ apart. The feeder containing the seeds 
1 was located between the two central perches and the adults and the juvenile had simultaneous

2 access to the seeds. When the juvenile was alone or separated from the adults, the cage was

3 divided in half by a transparent Plexiglas partition parallel to the perches and placed between

4 the two central perches. The nest remained in the compartment where the adults (when

5 present) were placed. Depending on the experimental situation, either only the compartment

6 with the juvenile contained a hemp seed feeder located against the transparent partition, or

7 both the compartment of the adults and that of the young contained seed in feeders placed

8 back to back, on either side of the partition. When adults were present but were not

9 demonstrators, the perch nearest the juveniles' compartment was removed to prevent the adults

10 from pecking at the partition. The seeds used throughout the experiment were carefully sorted

11 so that birds had only access to whole seeds that required husking. Each feeder contained 20

$12 \mathrm{~cm}^{3}$ of seed.

13 One hundred and twenty juveniles were assigned to the eight experimental conditions

14 (15 juveniles per condition). Within each experimental condition, each bird was observed 15 constantly for one hour. Observations took place between 09.00 and 13.00 hours. The eight 16 experimental conditions (see also Table.1) were as follows:

17 1) P-FI (parents - free interactions). The juvenile and its biological parents, which also reared 18 the young bird, were allowed to interact freely.

19 2) NP-FI (non-parents - free interactions). The juvenile and unfamiliar adults, which had 20 reared other young of the same age, were allowed to interact freely.

21 3) P-DS (parents - demonstrators separated). The juvenile and its biological parents were 22 separated by a transparent partition. They had simultaneous access to hemp on each side of the 23 partition. 
1 4) NP-DS (non-parents - demonstrators separated). The juvenile and unfamiliar adults were

2 separated by a transparent partition. They had simultaneous access to hemp on each side of the 3 partition.

4 5) P-NDS (parents - non-demonstrators separated). The juvenile and its parents were 5 separated by a transparent partition. Only the young bird, but not the parents, had access to 6 hemp near the partition.

7 6) NP-NDS (non-parents - non-demonstrators separated). The juvenile and unfamiliar adults 8 were separated by a transparent partition. Only the young bird, but not the adults, had access 9 to hemp.

10 7) JA-FC (juvenile alone in familiar cage). The juvenile was placed alone in the cage where it 11 had been reared and which was divided by a partition. Its parents had been previously 12 removed and the young bird had free access to hemp seeds on its side.

13 8) JA-UC (juvenile alone in unfamiliar cage). The juvenile was placed alone in a cage divided 14 by a partition in which it had free access to hemp. The cage was unfamiliar as it belonged to 15 unfamiliar birds, which had been reared there and then removed. measuring 30x30x35 cm in an unfamiliar environment. They were in acoustic and visual 18 isolation from adults and in visual isolation from other juveniles fed without seeds. They had a 19 feeder containing hemp as well as bird mash and drinking water. They remained in the cage until they had husked one seed or for a maximum of 32h. This duration is sufficient to check

21 whether seed handling had been acquired by young birds during their interaction with adults. 
1 During the first part of the experiment (familiarization with hemp seeds), the following

2 behaviors were recorded:

3 1) When the birds interacted freely, we quantified the number of agonistic and affiliative

4 interactions between the three birds (attacks, begging acts by the juvenile and feeding acts of

5 the young by the adults). We also measured the time spent at the hemp feeder by each of the

6 two adults and by the juvenile and the time spent by the juvenile at the feeder without the

7 adults, with either of the two adults or with both adults. We also noted whether the young

8 birds pecked small pieces of hemp kernel dropped from the bills of the adults.

9 2) In all situations (interaction free or not) we noted the juvenile's behavior with respect to the 10 seeds, i.e. the latency to pick up the first seed, the number of seeds picked up and the number 11 of seeds actually ingested after husking.

12 3) When adults were present and seeds available to them, we quantified their demonstration 13 activity in terms of the number of seeds they ingested after husking.

14 4) When young birds were separated from the adults (demonstrators or non- demonstrators), 15 we measured the time spent by juveniles on the perch located in the vicinity of the adult birds. During the second part of the experiment (verification of social transmission), we 17 recorded:

18 -i) the latency before picking up the first seed to evaluate familiarization with hemp.

19 -ii) the time elapsed before husking and eating the first seed to evaluate handling efficiency. 
1 As most values were not normally distributed, we used nonparametric statistics (Siegel and

2 Castellan 1988). Kruskall-Wallis one-way analysis of variance by ranks was used to compare

3 more than two groups, followed by the method of multiple comparisons when the null

4 hypothesis was rejected. For comparison of two groups, we used the Mann-Whitney U-test.

5 Matched pairs of observation were analyzed by means of the Wilcoxon signed ranks test.

6 Behavioral frequencies were compared by means of the chi-squared test with the Yates

7 correction for continuity. Percentages were compared to a random level (50\%) according to

8 Schwartz (1968). Statistical tests were two-tailed and the alpha level was set to 0.05. For

9 multiple comparisons, the alpha level was divided by the number of groups considered.

RESULTS

\section{Affiliative and agonistic behavior during free interactions}

14 We focused on the free interaction groups P-FI and NP-FI (parents and non-parents, 15 respectively). In both groups, the juvenile interacted freely with the adults (male and female) 16 which could be related (P-FI) or not (NP-FI). Taking both groups together ( $\underline{N}=30,15$ for P-FI 17 and 15 for NP-FI) we noted only one attack from the two non-parent adults towards a juvenile 18 male. No other aggressive behavior such as active chasing away of juveniles from the feeders 19 by the adults was observed.

During free interactions, sex and familiarity of the adults played a significant role in

21 juvenile feeding. The juveniles were always fed by the adult male. Twelve out of 15 juveniles 22 (eight males and four females) were fed by their fathers and two juveniles (one male and one 
1 female) were fed by an unfamiliar adult male. Thus, juveniles were more fed by their fathers

2 than by an unfamiliar male (comparison familiar versus unfamiliar, $2 \times 2 \chi^{2}{ }_{1}=11.84, \underline{\mathrm{P}}<0.001$ ).

3 Thirteen juveniles (six males and seven females) were observed begging from their fathers,

4 while two juveniles (one male and one female) begged from an unfamiliar adult (comparison

5 familiar versus unfamiliar, $\left.2 \times 2 \chi^{2}{ }_{1}=13.33, \underline{\mathrm{P}}<0.001\right)$.

Juveniles spent more time at the hemp feeder when they interacted freely with the familiar male and/or female than with unfamiliar adults (Fig. 1A). The difference of the

8 percentage of time (60 min) spent at feeder between both groups (P-FI and NP-FI) was highly

9 significant (Mann-Whitney $\underline{\mathrm{U}}$ test $\mathrm{Z}=4.2, \underline{\mathrm{N}}_{1}=\underline{\mathrm{N}}_{2}=15, \underline{\mathrm{P}}<0.0001$ ). More detailed examination revealed that $72 \%$ (interquartile range $67-100$ ) of the time spent by the juvenile at the hemp

11 feeder was with its father in P-FI group. This proportion dropped to $0 \%(0-12)$ in the case of 12 an unfamiliar male (NP-FI). The difference between the two values was again highly 13 significant (Mann-Whitney $\underline{\mathrm{U}}$ test $\mathrm{Z}=4.6, \underline{\mathrm{N}}_{1}=\underline{\mathrm{N}}_{2}=15, \underline{\mathrm{P}}<0.0001$ ). Such a difference was not 14 observed for female adults. Juveniles spent only 3\% of the time (0-7) with the familiar female 15 and 0\% (0-6) with an unfamiliar female (Mann-Whitney $\underline{\mathrm{U}}$ test $\mathrm{Z}=1.06, \underline{\mathrm{N}}_{1}=\underline{\mathrm{N}}_{2}=15, \underline{\mathrm{P}}=0.287$ ). 16 This shows that young birds visit the new source of food essentially in the company of 17 familiar males. This conclusion has to be taken cautiously because the short time spent by a 18 juvenile alongside its mother could result from the fact that the female was incubating 19 (median =51min/60; interquartile range 42-60) and was thus not available for joint feeding 20 activities. To test the juveniles' preference between father and mother, the time spent at the 21 hemp feeder by the young bird was normalized with respect to the time spent at the same place 22 by each adult (Fig. 1B). We found that juveniles preferred their fathers as a model rather than 23 their mothers (Wilcoxon signed-ranks test: $\underline{T}=6, \underline{N}=11, \underline{\mathrm{P}}<0.02$ ). 
1 opened by the adult (scrounging effect). Although the amount of kernel ingested could not be

2 determined, juveniles ate significantly more with their parents. Fourteen juveniles (7 males

3 and 7 females) ate pieces of kernel during interactions with their parents while only three (1

4 male and 2 females $)$ did so with an unfamiliar adult $\left(2 \times 2 \chi^{2}{ }_{1}=13.74, \underline{\mathrm{P}}<0.001\right)$. During the free

5 interactions, most juveniles (13 out of 15, i.e. 7 males and 6 females) that interacted with their

6 parents husked seeds by themselves and consumed the kernels while only few juveniles (3 of

7 15, i.e. 2 males and 1 female) that interacted with unfamiliar adults did so $\left(2 \times 2 \chi^{2}{ }_{1}=10.85\right.$,

$8 \underline{\mathrm{P}}<0.001)$. Familiarity was thus important for seed husking as free interactions with familiar

9 adults favored seed consumption $\left(2 \times 2 \chi{ }^{2}{ }_{1}=10.85, \underline{\mathrm{P}}<0.001\right)$. The sex of the juvenile did not 10 appear to have any influence on seed husking.

\section{Behavior of the juveniles towards the seed during the various kinds of interactions}

13 We first considered the effect of cage familiarity. Two groups of juveniles were studied, one 14 in which the juvenile was alone in the familiar cage in which it was reared (JA-FC group) and another in which it was alone in an unfamiliar cage (JA-UC group). Familiarity with the cage in which the test took place did not affect seed use by the juveniles, as the great majority of young birds did not pick up seed in either context. Only one bird out of 15 handled seed in the JA-UC situation and none in the JA-FC situation. Thus, both groups were excluded from further analyses. In the six remaining groups (P-FI, NP-FI, P-DS, NP-DS, P-NDS, and NPNDS; see Methods and Table 1), we focused on three main variables related to seed

21 consumption, which were the time elapsed before picking up the first seed, the number of 22 seeds picked up and the number of seeds consumed after husking. 
1 Time elapsed before picking up the first seed

2 The latency to pick up the first seed (Fig. 2A) varied between the experimental groups

3 (Kruskal-Wallis test: $\underline{\mathrm{H}}_{5}=47.15, \underline{\mathrm{N}}=90, \underline{\mathrm{P}}<0.0001$ ). The multiple comparison test (Siegel and

4 Castellan 1988 pp.206-216) showed that during free interactions, familiarity with the adults

5 shortened the time required before the first seed was picked up (P-FI vs. NP-FI, observed

6 difference $\mathrm{d}=38.9, \underline{\mathrm{P}}<0.05$; critical difference: $=26.9$ for $\underline{\mathrm{P}}=0.05)$. The presence of a dividing

7 partition did not modify the latency before a seed was picked up, irrespective of the familiarity

8 of the demonstrators (parents: P-FI vs. P-DS, $d=6.03, \underline{\mathrm{P}}>0.05$; non-parents: NP-FI vs. NP-DS,

$9 \mathrm{~d}=1.3, \underline{\mathrm{P}}>0.05)$. Young birds had a decreased latency when they could see their parents

10 engaged in demonstrating activities (P-FI vs. P-NDS $\mathrm{d}=34.9, \underline{\mathrm{P}}<0.05$ and P-DS vs. P-NDS

$11 \mathrm{~d}=40.9, \underline{\mathrm{P}}<0.05)$. This effect was absent in the case of juveniles in the presence of unfamiliar

12 adults (NP-FI vs. NP-NDS $d=9.2, \underline{\mathrm{P}}>0.05$ and NP-DS vs. NP-NDS, $d=10.6, \underline{\mathrm{P}}>0.05$ ). The

13 latency before picking up the first seed was similar when the adults were not demonstrators

14 (P-NDS vs. NP-NDS, $\mathrm{d}=5.1, \underline{\mathrm{P}}>0.05)$.

Number of seeds picked up

17 The number of seeds picked up (Fig. 2B) varied between the experimental groups (Kruskal-

18 Wallis test: $\left.\underline{\mathrm{H}}_{5}=49.23, \underline{\mathrm{N}}=90, \underline{\mathrm{P}}<0.0001\right)$. The juveniles, which interacted freely with adults,

19 picked up more seeds with their parents than with unfamiliar adults (P-FI vs. NP-FI, observed

20 difference $\mathrm{d}=35.6, \underline{\mathrm{P}}<0.05$, critical difference: $=26.9$ for $\mathrm{P}=0.05)$. The number of seeds picked

21 up was not modified by the separating partition, neither in the presence of familiar (P-FI vs. P-

22 DS, $\mathrm{d}=9.57, \underline{\mathrm{P}}>0.05$ ) nor unfamiliar demonstrators (NP-FI vs.NP-DS, $\mathrm{d}=4.2, \underline{\mathrm{P}}>0.05$ ).

23 Observing the feeding activity of the parents increased seed manipulation by the juvenile, 
1 regardless of the nature of the interactions (free or not) (P-FI vs. P-NDS, $d=27.4 ; \underline{\mathrm{P}}<0.05$ and

2 P-DS vs. P-NDS, $\mathrm{d}=35.9$; $\underline{\mathrm{P}}<0.05)$. Observing non-familiar adults had no effect on picking up

3 seed (NP-FI vs. NP-NDS, $d=5.8, \underline{P}>0.05$ and NP-DS vs. NP-NDS, $d=5.43, \underline{P}>0.05$ ).

4 Familiarity with non-demonstrator adults had no effect if animals were not engaged in

5 demonstrating activities (P-NDS vs. NP-NDS, $\mathrm{d}=14.6, \underline{\mathrm{P}}>0.05$ ).

$7 \quad$ Number of seeds consumed after husking

8 An analysis of the number of seeds consumed after husking (Fig. 2C) revealed trends similar 9 to those found for latency and number of seeds picked up. The number of seeds consumed varied between the experimental groups (Kruskal-Wallis test: $\underline{\mathrm{H}}_{5}=62.69, \underline{\mathrm{N}}=90, \underline{\mathrm{P}}<0.0001$ ).

11 The ability to observe the parents consuming hemp promoted consumption of the seed by the 12 juvenile, regardless of the nature of interactions (free or not) (P-FI vs. P-NDS, d=40.4, $13 \underline{\mathrm{P}}<0.05$; P-DS vs. P-NDS, $\mathrm{d}=43.8, \underline{\mathrm{P}}<0.05)$. This again underlines the importance of observing 14 the familiar adults feeding (P-FI vs. P-DS, $\mathrm{d}=3.4, \underline{\mathrm{P}}>0.05$ ). Neither observation through the 15 Plexiglas partition nor free interaction but with unfamiliar adults with access to seed facilitated 16 hemp consumption by the young (NP-DS vs. NP-NDS, $d=5.1 ; \underline{\mathrm{P}}>0.05$ and NP-FI vs. NP-NDS, $17 \mathrm{~d}=6.7, \underline{\mathrm{P}}>0.05)$. Husking behavior was only facilitated in the presence of familiar 18 demonstrators (P-FI vs. NP-FI, $\mathrm{d}=38.9, \underline{\mathrm{P}}<0.05$ and P-DS vs. NP-DS, $\mathrm{d}=46.3 ; \underline{\mathrm{P}}<0.05$ ). Demonstrating activity of the adults

21 In the four situations in which hemp was available to the adults, all males ingested seed. In the presence of a familiar juvenile, eleven females out of fifteen left their nest and ate seeds in 
1 situation P-FI and two females in situation P-DS, while all females did it in the presence of an

2 unfamiliar juvenile (NP-FI and NP-DS). Taken as a whole, fewer females ingested hemp in

3 the presence of their offspring than in the presence of unfamiliar young (P-FI and P-DS vs.

4 NP-FI and NP-DS; $\left.2 \times 2 \chi^{2}{ }_{1}=6.64, \underline{\mathrm{P}}<0.001\right)$. Moreover, in each of the two situations in which

5 birds interacted freely (P-FI and NP-FI groups), eight pairs of adults consumed hemp

6 simultaneously. When juveniles were separated from adults, a single familiar mother ate seed

7 alongside the adult father, while ten unfamiliar adult pairs ingested seeds together. The

8 number of demonstrating adults (either one adult or two) cannot account for the differences

9 observed in the behavior of the young birds towards the seed.

The number of seeds ingested by the males after husking (Fig. 3A) varied between the

11 experimental groups (Kruskal-Wallis test: $\underline{\mathrm{H}}_{3}=18.04, \underline{\mathrm{N}}=60, \underline{\mathrm{P}}<0.0004$ ). We did not find

12 differences between the feeding activity of familiar and unfamiliar adult males during free

13 interactions (P-FI vs. NP-FI, observed difference $\mathrm{d}=4.80, \underline{\mathrm{P}}>0.05$, critical difference: 16.3 for

$14 \mathrm{P}=0.05$ ). Males ate more seeds when separated from familiar juveniles (P-FI vs. P-DS, $d=17.1$,

$15 \underline{\mathrm{P}}<0.05)$. This effect did not occur when juveniles were unfamiliar (NP-FI vs. NP-DS, $d=3.20$,

$16 \underline{\mathrm{P}}>0.05)$.

The number of seeds ingested by the females after husking (Fig. 3b) also varied between experimental groups (Kruskal-Wallis test: $\underline{\mathrm{H}}_{3}=29.46$, $\underline{\mathrm{N}}=60, \underline{\mathrm{P}}<0.0001$ ). Feeding activity of adult females did not depend on familiarity with juveniles when interacting freely with them (P-FI vs. NP-FI, d=9.86, $\underline{\mathrm{P}}>0.05$ ). Demonstrating activity decreased when the mothers were separated from their offspring by a partition (P-FI vs. P-DS, $d=21.3, \underline{P}<0.05$ ). No effect of separation was found in adult females accompanied by unfamiliar juveniles (NPFI vs. NP-DS, $\mathrm{d}=3.50, \underline{\mathrm{P}}>0.05)$. Thus, the behavior of young birds towards seed was not a simple consequence of the intensity of the demonstrating activity of the adults of each sex. 
2 Time spent by the juvenile close to inaccessible familiar or unfamiliar adults

3 Here we consider the effect of familiarity and demonstrating activity of adults on the tendency

4 of young birds to approach the partition separating them from the adults. Juveniles alone in an

5 unfamiliar or familiar cage (groups JA-UC and JA-FC) did not prefer the perch close to the

6 partition but chose randomly between it and the more distant perch (comparisons with a

7 random chance level of 50\%: $\underline{\text { NS}}$; Schwartz, 1968).

The attraction exerted by the adults on the juvenile (Fig. 4) was measured by the time

9 spent by the young on the perch close to the partition when the interaction was not free.

10 Statistical analysis showed that this time varied according to the experimental conditions in

11 the four groups where adults were present (Kruskal-Wallis test: $\underline{H}_{3}=31.93, \underline{N}=60, \underline{P}<0.0001$ ).

12 Post-hoc tests revealed that young birds were similarly attracted by adults, either familiar or 13 not, when these adults did not act as demonstrators (P-NDS vs. NP-NDS; observed difference $14 \mathrm{~d}=6.53, \underline{\mathrm{P}}>0.05$; critical difference: 16.3 for $\underline{\mathrm{P}}=0.05)$. When adults were demonstrators, 15 juveniles were more attracted by their parents (P-DS vs NP-DS $d=34.8, \underline{\mathrm{P}}<0.05$ ). The young 16 birds stayed close to their parents when acting as demonstrators or not (P-DS vs P-NDS; $17 \mathrm{~d}=9.80, \underline{\mathrm{P}}>0.05$ ), but tended to move away from the separating partition when unfamiliar 18 adults occupied the hemp feeder (NP-DS vs. NP-NDS $d=18.5, \underline{\mathrm{P}}<0.05$ ). Verification of social transmission of seed use in juveniles

21 Isolation of juveniles previously exposed to hemp seed in an unfamiliar environment allowed verifying the occurrence of social transmission of the use of this new food. The control groups 
1 JA-FC and JA-UC (absence of adults during prior exposure to seeds) differed strongly from

2 the six other groups. Only two juveniles picked up and husked seeds after transfer to another

3 environment in the JA-FC situation and one in the JA-UC situation. These results show that

4 the presence of an adult is critical for the juveniles to consume seeds subsequently. Owing to

5 the effective lack of data, we excluded the two control groups from further analysis.

6 Comparisons were made between the six groups where the juvenile had been with a

7 demonstrator.

We found no effect of the kind of interaction with adults on the latency to pick up the

9 first seeds by isolated juveniles (Kruskal-Wallis test: $\underline{\mathrm{H}}_{5}=5.38, \underline{\mathrm{N}}=90, \underline{\mathrm{P}}=0.37$ ). Familiarization with seeds resulted from the mere presence of adults, regardless of their familiarity (Fig. 5A).

The time elapsed before consuming the first seed (Fig. 5B) varied significantly with the experimental situation (Kruskal-Wallis test: $\underline{\mathrm{H}}_{5}=38.46, \underline{\mathrm{N}}=90, \underline{\mathrm{P}}<0.0001$ ). Isolated juveniles husked seed earlier in situations in which the parents had previously acted as demonstrators than in situations where in which the parents were simply present (P-FI vs. P-NDS, d=34.0, $\underline{\mathrm{P}}<0.05$ and $\mathrm{P}-\mathrm{DS}$ vs. $\mathrm{P}-\mathrm{NDS}, \mathrm{d}=36.9, \underline{\mathrm{P}}<0.05$; critical difference: 26.9 for $\underline{\mathrm{P}}=0.05)$. Separation 16 from the parents during the interaction period did not have a long lasting effect (P-FI vs. P-DS, $\mathrm{d}=2.9, \underline{\mathrm{P}}>0.05$ ). Being familiar with the adults during the first exposure to seed did not accelerate later husking if the adults were not demonstrators (P-NDS vs. NP-NDS, $\mathrm{d}=2.0$, $\underline{\mathrm{P}}>0.05)$. Similarly, if demonstrators were unfamiliar, no effect was found on the time elapsed before consuming the first seed (NP-FI vs. NP-NDS, $\mathrm{d}=2.2, \underline{\mathrm{P}}>0.05$, and NP-DS vs. NP-NDS,

$21 \mathrm{~d}=2.9, \underline{\mathrm{P}}>0.05)$. Seed handling efficiency in groups P-FI and P-DS resulted, therefore, from observing and acting alongside familiar adults and not from simple familiarization with the new food. 


\section{DISCUSSION}

2 The results obtained in the present investigation show that familiarization with seed and seed

3 handling skills are transmitted through distinct routes from experienced adults to juveniles

4 during free interactions. Familiarization of juveniles with an unknown food occurs through the

5 mere presence of adults familiar or unfamiliar, while acquisition of efficient handling skills

6 requires simultaneous access to the seed by the juvenile and a familiar adult. This long-lasting

7 effect on handling efficiency in juveniles does not result from the simple observation of the

8 familiar adult's behavior as revealed by a previous experiment using adult males as

9 demonstrators (Cadieu and Cadieu 2004). However, the results obtained in that study did not

10 provide a clear explanation of the mechanisms involved in the free interactions. More

11 important, they were obtained in the framework of dyadic interactions (Cadieu and Cadieu

12 2004), thus excluding any possibility of determining whether both parents played the same

13 role as demonstrators when acting together. In the present work, we studied free triadic

14 interactions (using a juvenile and a pair of adults familiar or unfamiliar) in order to avoid this

15 caveat. In this context, the juvenile prefers to associate with the father (familiar male).

16 Comparing free and non-free interactions, with or without demonstrative activity, 17 enabled us to study the ways in which free interactions act and to determine the particular role 18 of each parent in social transmission. As mentioned above, allowing a juvenile to access the 19 seed in the presence of non-demonstrator adults did not favor handling, irrespective of the 20 level of familiarity. These results led us to reject the hypothesis stating that the mere presence

21 of the adults suffices to promote complete social transmission. Furthermore, they also discard 22 the hypothesis positing that learning handling skills results from following the parents to a 23 feeding ground. This hypothesis had been put forward to account for the acquisition of various 24 techniques of mussel opening in the young oystercatcher (Haematopus ostralegus; Norton- 
1 Griffis 1966; Galef 1996). In the canary, the familiar demonstrator must actually perform the

2 feeding activity during the interaction phase to favor the acquisition of the handling tasks.

3 Acquisition of husking by the young bird in the presence of its father is not, however, the

4 result of the young having access to husked kernels. An explanation can be found in the fact

5 that the short or long-lasting effects of the free or non-free interactions are the same when

6 there is a partition. Scrounging had, therefore, neither a positive nor a negative effect, even

7 though the juveniles did consume scraps of kernel husked by the father. Husking appears to be

8 acquired through coordination of the activities of the young bird and its parent: in situations FI

9 and DS the juvenile picked up seed earlier and handled more seeds than in any other situation.

10 Furthermore, it is also in these two situations that the young husked seed and reached the

11 reward without help. In the canary, the co action between young birds and familiar adults

12 arises from social facilitation (or engagement in the same action, Clayton 1978) and plays a

13 role in the acquisition of a handling technique and not merely in the recognition of new food

14 resources as reported by Murton (1971) and Forkman (1991).

The demonstrating activity of the different categories of adult (male, female, familiar, unfamiliar) motivated the juvenile to attempt to husk seed to different extents. The degree of motivation depended on the role played by the adult with respect to the young and also on the active choice of a feeding model by the young. During free interactions, the adults of either sex, familiar or not, never attacked the juvenile. Therefore, tolerance of the demonstrator towards the juvenile does not appear to be a key factor in social transmission in the canary.

When the juvenile was separated from unknown adults not engaged in demonstrating activities by the Plexiglas partition, it approached and picked up the seeds in the same way as when it was confronted with its parents. In contrast, if the unknown adults had also access to the seeds, the juvenile moved away and did not interact directly with them (Fig. 4). In spite of 
1 the adults' lack of aggressiveness, the young birds seemed to fear the unknown birds. This

2 probably prevented them from learning to husk the seed through social facilitation but did not

3 prevent them from becoming familiar with the object to be manipulated. In a previous study

4 we showed that the presence of unfamiliar females tended to reduce fear in juveniles when

5 interacting with them in the absence of unfamiliar males (Cadieu and Cadieu 2002). During

6 triadic interactions, the added presence of an unfamiliar male seems to prevent this effect in

7 juveniles, which stayed away from the pair of unfamiliar adults and therefore, did not learn

8 with the unfamiliar female. This result shows that conclusions obtained in the framework of

9 dyadic interactions are only partially valid when the animals are placed in the appropriate, 10 natural context of triadic interactions.

11 Familiarity is not the only factor that leads the juvenile to learn preferentially with 12 certain individuals. During free interactions, the young associated preferentially with the 13 father to eat, i.e. with the bird that fed it after fledging and not with the mother, which was 14 busy incubating the next clutch. Even though the mother did not exhibit any aggressive 15 behavior towards the juvenile, the efficiency of the social transmission of husking was 16 independent of the female's feeding activity, which was quite low when the demonstrator was 17 behind the partition (DS situation, Fig. 3). As handling skills were effectively transmitted to 18 the juvenile in this situation (FI and DS did not differ: Fig. 5), it was therefore the male that 19 ensured the transmission. In addition, the father, in contrast to the mother, actually encourages the juvenile to act

21 (as seen in situation DS). The males show increased activity in the presence of their young, 22 while females exhibit a lower level of activity. The young birds tend to approach and learn 23 seed husking from the familiar adult, which looks after it once fledged. The fact that young 24 birds frequently use the same food sources as familiar adult males has already been observed 
1 in budgerigars (Melopsittacus undulates; Stamps et al., 1990) but the effects of such a

2 common use of food sources on the social transmission of feeding skills have not been studied 3 so far.

Other studies have shown that young naïve birds (Smith et al. 2002) and primates (Biro

5 et al. 2003) choose their model during social learning, in semi-natural conditions. The

6 preponderant role of familiar adult males in the transmission of information about food has

7 also been underlined in other passerines (Benskin et al. 2002; Katz and Lachlan 2003).

8 However, the latter studies only considered the transmission of a preference through

9 observation of an experienced conspecific and not, as in the present study, through the 10 interactive acquisition (by coaction) of the skills necessary to ensure the young bird's 11 transition towards complete and successful emancipation. The survival of the juveniles during 12 this transition to independence depends, therefore, on paternal care since one of the roles of 13 the father is to serve as a model for the recognition and handling of food whereas the role of 14 females is to invest in the next clutch. The familiar male is able to act as a model because of 15 the attraction it exerts on the young canary, which chooses it actively and freely as a model 16 rather than being forced to choose it owing to the aggression of the other adults towards 17 unknown juveniles.

\section{ACKNOWLEDGMENTS}

21 We are grateful to M. Giurfa for his helpful comments on the manuscript. We thank G. Latil

22 for technical assistance. All the experimental procedures comply with French laws governing

23 experiments on animals. Experiments on canaries were carried out in our laboratory under 
1 license from the French Ministry of Agriculture and Forestry. Support of CNRS and the

2 University Paul Sabatier is acknowledged.

\section{REFERENCES}

Beauchamp G, Kacelnik A (1991). Effects of the knowledge of partners on learning rates in Zebra finches (Teaniopygia guttata). Anim Behav 41: 247-253.

Benskin CMH, Mann NI, Lachlan RF, Slater PJB (2002) Social learning directs feeding preferences in the Zebra finch, (Taeniopygia guttata). Anim Behav 64: 823-828

Biro D, Inoue-Nakamura N, Tonooka R, Yamakoshi G, Sousa C, Matsuzawa T (2003) Cultural innovation and transmission of tool use in wild chimpanzees: evidence from field experiments. Anim. Cogn 6: 213-223.

Cadieu JC, Cadieu N (1996) Influence of some interactions between fledglings and adults on the food choice in young canaries (Serinus canarius) J Ethol 14: 99-109

Cadieu N, Cadieu JC (1998) Is food recognition in an unfamiliar environment a long-term effect of stimulus or local enhancement? A study in the juvenile canary Behav Process 43: 183-192.

Cadieu N, Cadieu JC (2002) Is use of a novel food source by young canaries (Serinus canarius) influenced by the sex and familiarity of the adult demonstrator? Behaviour 139: 825-846. 
1 social transmission in the young canary. Anim Behav 67: 1051-1057.

2 Cadieu JC, Cadieu N, Lauga J (1995a) Local enhancement and seed choice in the juvenile

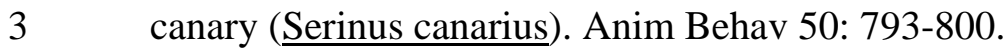

4 Cadieu JC, Cadieu N, Médioni J (1995b) Parental influence on food familiarisation in the 5 fledgling canary (erinus canarius) and its long-term effect. Ethol Ecol Evol 7: 265-270.

6 Caldwell CA, Witten A (2003) Scrounging facilitates social learning in common 7 marmosets, (Callithrix jacchus). Anim Behav 65: 1085-1092.

8 Caro T M (1980). Predatory behaviour in domestic cat mothers. Behaviour 74: 128-147.

9 Chesler P (1969) Maternal influence in learning by observation in kittens. Science 166: $10 \quad 901-903$.

11 Clayton D A (1978) Socially facilitated behavior. Q Rev Biol 53: 373-391

12 Coussi-Korbel S, Fragaszy DM (1995) On the relation between social dynamics and social 13 learning. Anim Behav 50: 1441-1453.

14 Davies NB (1976) Parental care and the transition to independent feeding in the young 15 spotted flycatcher (Musicapa striata). Behaviour 59: 280-295.

16 Diamond J (1987) Learned specializations of birds. Nature 330: 16-17.

17 Forkman B (1991) Social facilitation is shown by gerbils when presented with novel but 18 not with familiar food. Anim Behav 42: 860-861.

19 Galef BG Jr 1996 The adaptive value of social learning: a reply to Laland. Anim Behav 20 52: 641-644. 
1 Giraldeau LA, Lefebvre L (1987) Scrounging prevents cultural transmission of food-

2 finding behaviour in pigeons. Anim Behav 35: 387-394.

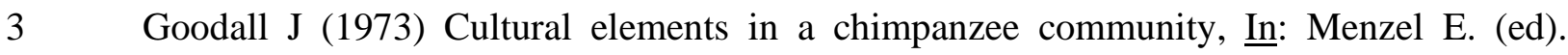

4 Precultural Primate Behaviour. Karger, Basel, pp144-184.

5 Hatch KK, Lefebvre L (1997) Does father know best? Social learning from kin and non$6 \quad$ kin juvenile ringdoves. Behav Process 41: 1-10.

$7 \quad$ Katz M, Lachlan RF (2003) Social learning of food types in Zebra finches (Taenopygia 8 guttata) is directed by demonstrator's sex and feeding activity. Anim Cogn 6: 11-16.

9 Meinertzhagen R (1954) The education of young ospreys. Ibis 96: 153-155. Midford PE, Hailman JP, Woolfenden GE (2000) Social learning of a novel foraging patch in families of free-living Florida scrub-jays. Anim Behav 59: 1199-1207.

Murton R K (1971) The significance of a specific search image in the feeding behaviour of the wood-pigeon. Behaviour 40: 10-42.

Nicol CJ, Pope SJ (1996) The maternal feeding display of domestic hens is sensitive to perceived chick error._Anim Behav 52: 767-774.

Norton-Griffiths M (1966) Some ecological aspects of the feeding behaviour of the oystercatcher ( 412-423.

Schwartz D (1968) Méthodes statistiques à l’usage des médecins et des biologistes. Paris: Flammarion. 
1 junglefowl (Gallus gallus spadiceus). Anim Behav 25: 594-601.

2 Siegel S, Castellan NJ (1988) Nonparametric Statistics for the Behavioral Sciences. 2nd 3 Edn. Toronto: McGraw - Hill.

4 Smith VA, King A P, West M J (2002) The context of social learning: association patterns 5 in a captive flock of brown-headed cowbirds. Anim Behav 63: 23-35.

6 Stamps J, Clark A, Kus B, Arrowood P (1990) Social relationships of fledgling $7 \quad$ budgerigars, (Melopsitticus undulatus). Anim Behav 40: 668-700.

8 Sutherland WJ (1998) The importance of behavioural studies in conservation biology. $9 \quad$ Anim Behav 56: 801-809.

10 Terkel J (1996) Cultural transmission of feeding behavior in the black rat (Rattus rattus).

11 In: Heyes CM, Galef BG Jr (eds) Social Learning in Animals: the Roots of Culture New $12 \quad$ York Academic Press. pp 17-47

13 Trivers RL (1974) Parent-offspring conflict. Amer Zool 12: 249-264.

14 Wauters AM, Richard-Yris MA, Pierre JS, Lunel C, Richard JP (1999) Influence of chicks 15 and food quality on food calling in broody domestic hens. Behaviour 136: 919-933. 


\section{FIGURE LEGENDES}

2 Figure 1: The median percentages ( \pm one quartile) of time spent by juveniles interacting

3 freely with a pair of adults at the hemp feeder. 1A) Percentage of the total time of observation

4 (60 min) spent by juveniles in interacting with their parents (P-FI) or with non-parents (NP-

5 FI). 1B) Percentage normalized with respect to the time spent at the hemp feeder by the 6 familiar male $(\mathrm{J} / \mathrm{M})$ and the familiar female $(\mathrm{J} / \mathrm{F})$ in the group P-FI.

$7 \quad$ Figure 2: The median latency ( \pm one quartile) to pick up the first seed $(\mathrm{A})$ and the median 8 numbers of seeds picked up per hour (B) and ingested after husking (C) in young canaries 9 during various interactions with their parents (P) or a pair of non-parents (NP): free 10 interactions with the adults (FI), demonstrators separated by a partition (DS), non11 demonstrating adults separated (NDS). Bars with a common letter do not differ significantly.

12 Figure 3: Demonstrating activity of adult male (A) and female (B) canaries. The median 13 number of seeds ( \pm one quartile) eaten per hour by parents (P) or non-parents (NP) during 14 various interactions with juveniles: free interactions with the adults (FI), demonstrators separated by a partition (DS). Bars with a common letter do not differ significantly.

Figure 4: The median time ( \pm one quartile) spent by juvenile canaries on the perch close to

17 their parents (P) or to non-parents (NP) when separated by a partition from demonstrating 18 adults (DS) and non-demonstrating adults (NDS). Bars with a common letter do not differ 19 significantly.

20 Figure 5: The median latency ( \pm one quartile) to pick up the first seed (A) and to ingest seed 21 after husking (B) in juveniles isolated after various interactions with their parents (P) or a pair 22 of non-parents (NP): free interactions with the adults (FI), demonstrators separated by a 23 partition (DS), non-demonstrating adults separated (NDS). 
TABLE 1

\section{Table1 Experimental conditions}

TYPE OF INTERACTION WITH

THE PAIR OF ADULTS
FAMILIARITY WITH THE SOCIAL OR PHYSICAL ENVIRONMENT

Free interactions with a

P-FI

NP-FI

demonstrating pair of adults

Interactions with a demonstrating pair of adults separated by

P-DS

NP-DS

Plexiglas partition

Interactions with a non-demonstrating pair of adults separated from juvenile P-NDS NP-NDS by a Plexiglas partition

Absence of a pair of adults. Juveniles alone in a familiar or unfamiliar cage 
FIG 1

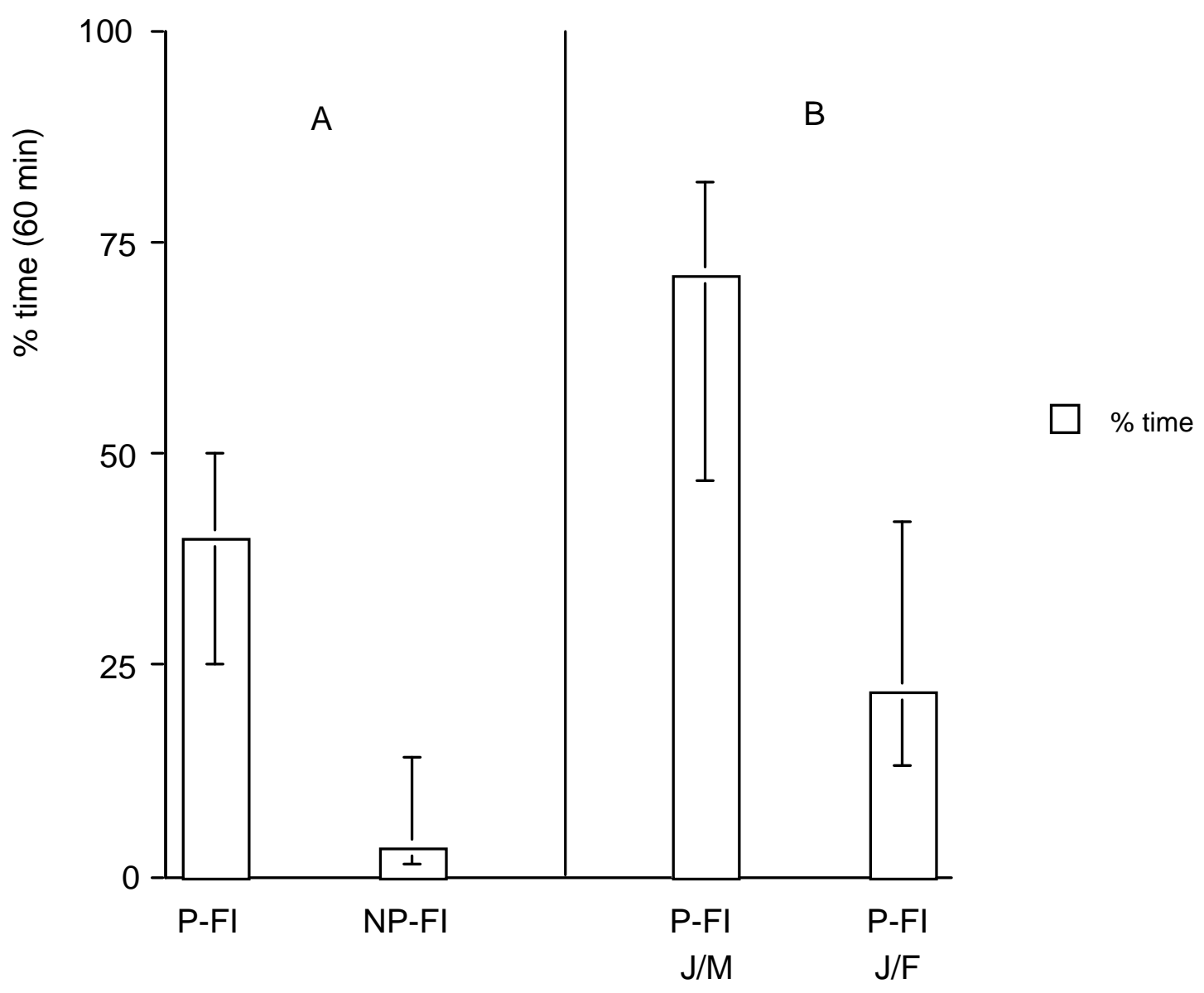

Groups 
FIG 2

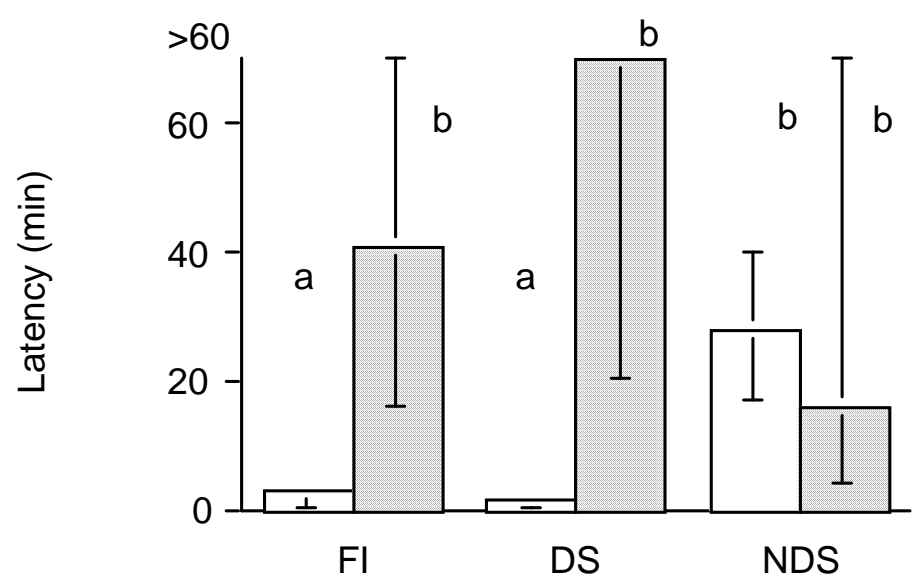

A

$\square$ PARENTS (P)

NON-PARENTS (NP)

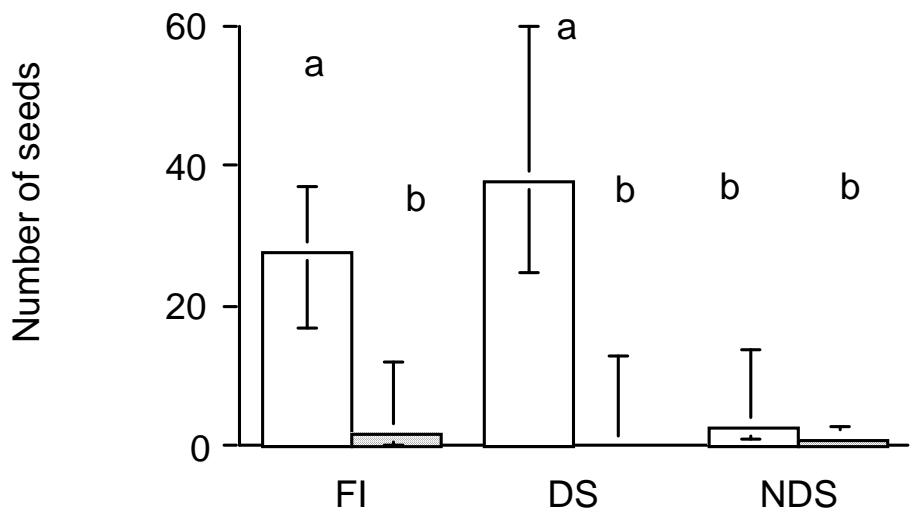

B

PARENTS (P)

NON-PARENTS (NP)

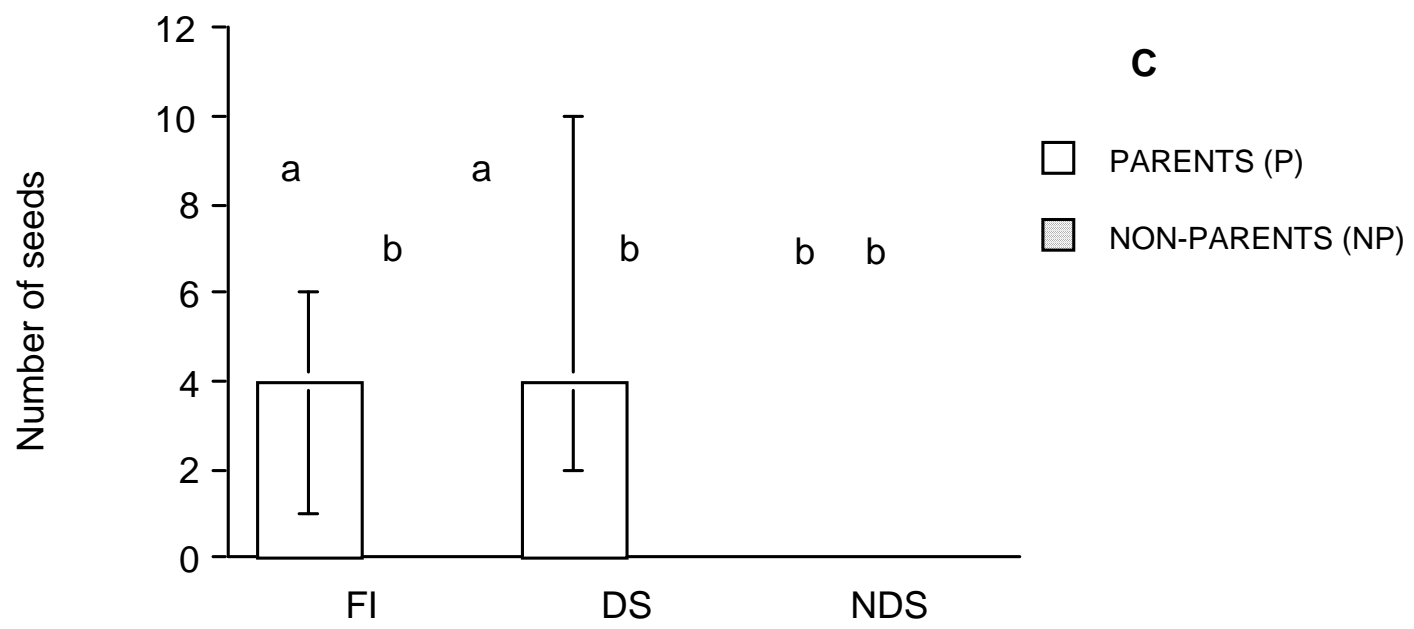

Groups 
FIG 3
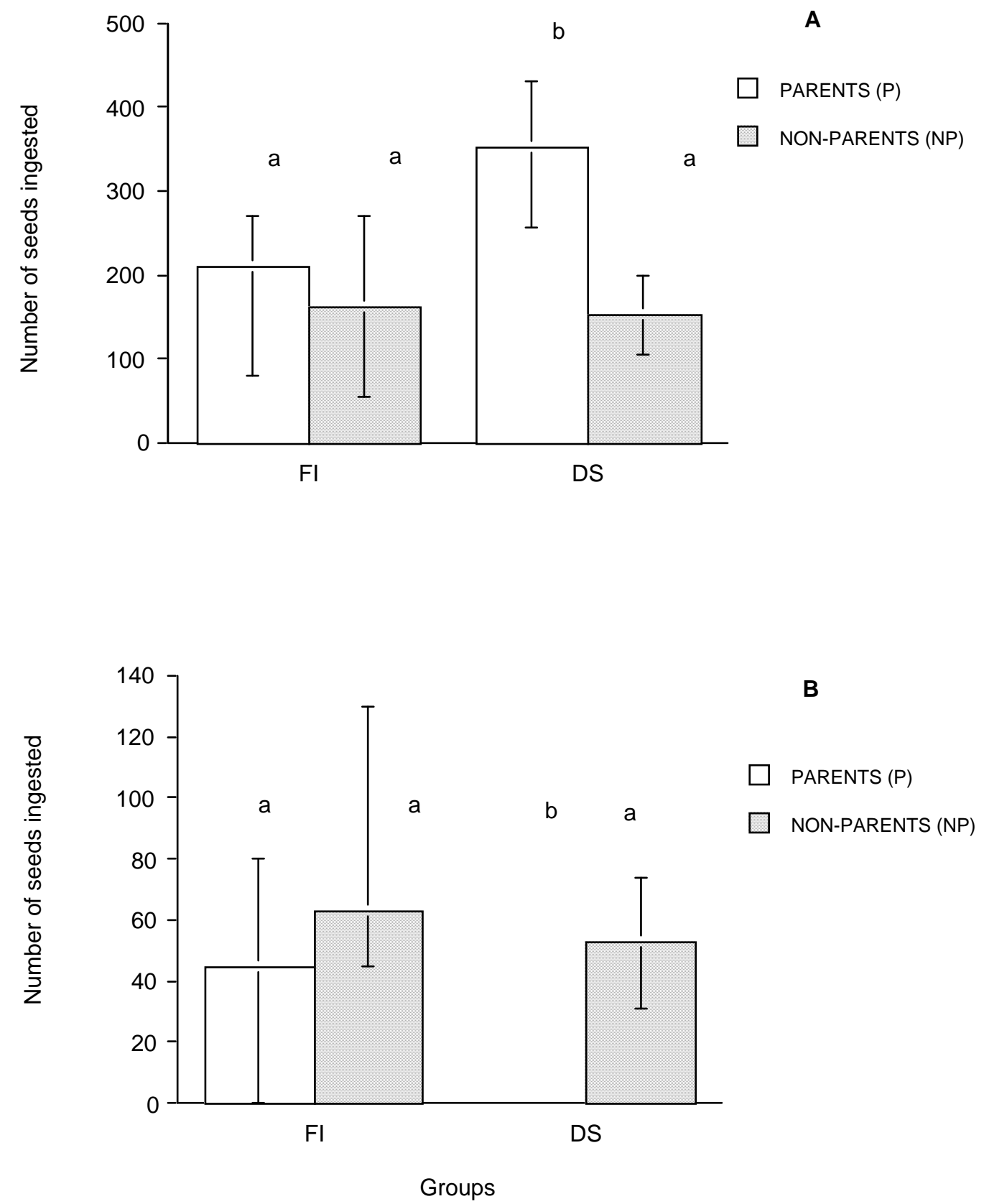
FIG 4

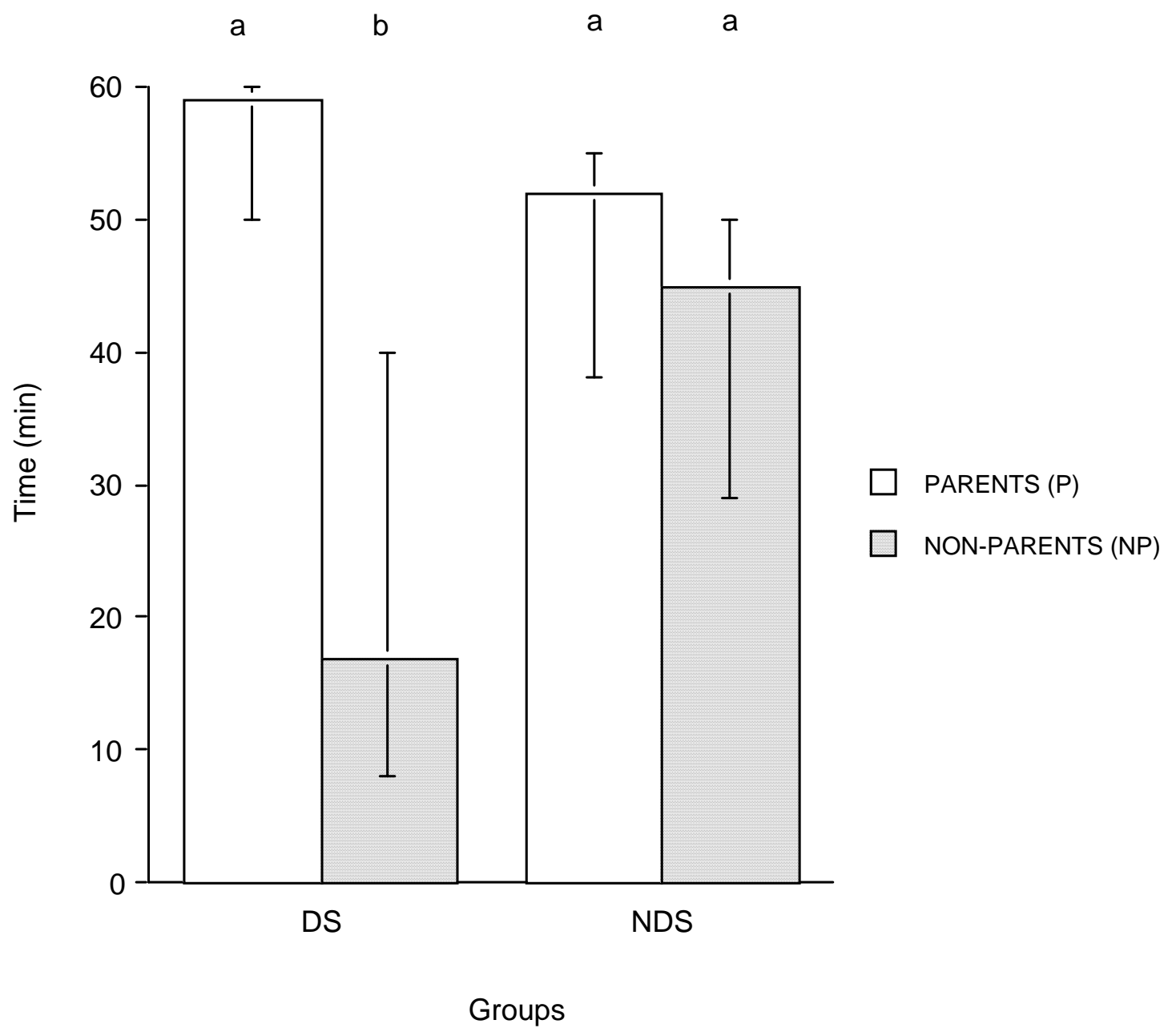


FIG 5

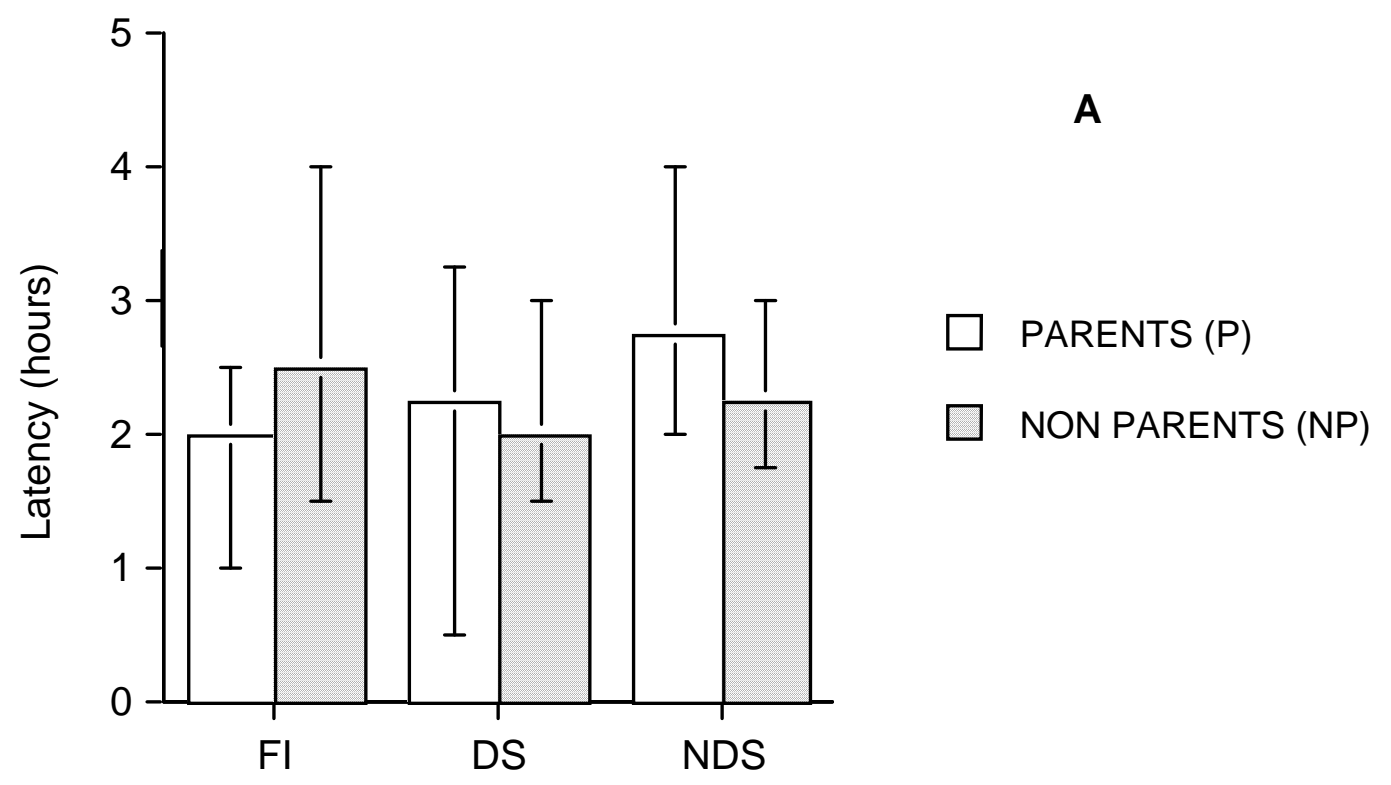

B

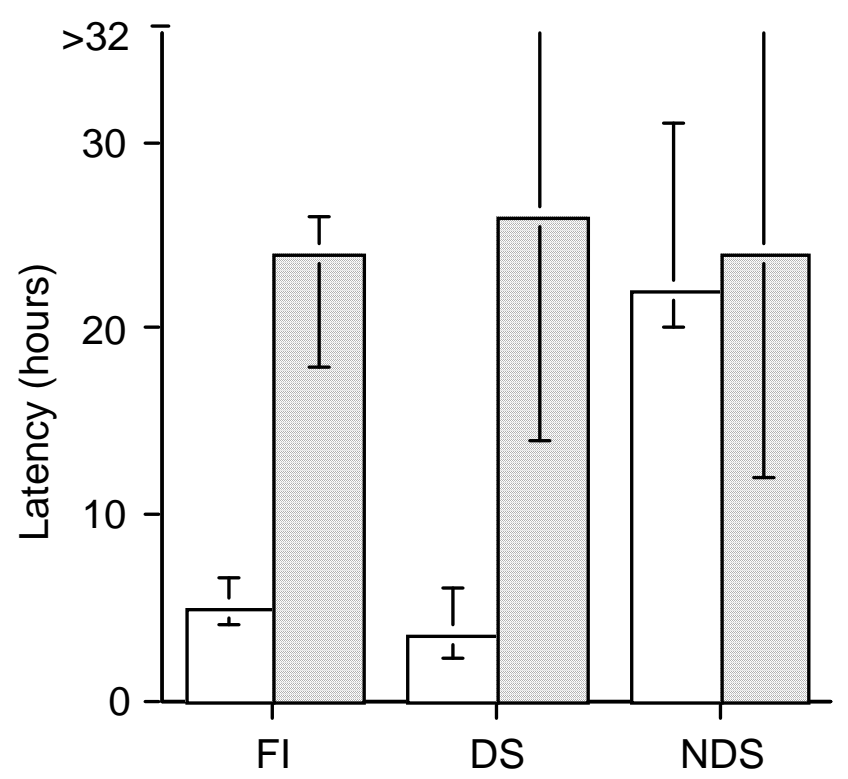

$\square$ PARENTS (P)

$\square$ NON PARENTS (NP)

Groups 
